\title{
The relationship between serum uric acid within the normal range and $\beta$-cell function in Chinese patients with type 2 diabetes: differences by body mass index and gender
}

\author{
Xing Zhong Equal first author, 1， Deyuan Zhang Equal frrst author, 1 , Lina Yang ${ }^{1}$, Yijun Du ${ }^{1}$ ， Tianrong Pan ${ }^{\text {Corresp. } 1}$ \\ 1 Department of Endocrinology, The Second Affiliated Hospital of Anhui Medical University, He Fei, Anhui Province, China \\ Corresponding Author: Tianrong Pan \\ Email address: pantianrong1968@163.com
}

Background: Elevated serum uric acid (SUA) has a positive correlation with insulin secretion and insulin resistance indexes. However, whether weight- and gender-specific differences regarding the relationship between SUA within the normal range and $\beta$-cell function and insulin resistance exist is unknown in T2DM patients.

Methods: Three hundreds and eighty patients with type 2 diabetes were divided into two groups as overweight/obesity $(n=268)$ and normal weight $(n=112)$. Each group were again divided into low (LSUA) and high normal SUA (HSUA). The HbAlc, C-peptide, SUA, creatinine, and lipids profiles were measured. HOMA2IR and HOMA\%2B were estimated using fasting glucose and C-peptide by homeostasis model assessment (HOMA). Pearson's correlations and multiple linear regression analyses were conducted to assess the associations between SUA levels and islet function indexes.

Results: In overweight/obesity subgroup, the levels of BMI, FCP, P2HCP, FCPI, PPCPI, $\triangle \mathrm{C}$-peptide, HOMA2\%B and HOMA2IR were higher in HSUA group than in LSUA group. In contrast, the HbA1C, FBS, and P2hBS were lower in HSUA than in LSUA. In normal weight subgroup, there were on differences between the HSUA than LSUA group in terms of clinical characteristics. Pearson's correlations indicated that there were no significant correlations between SUA and insulin secretory capacity in normal weight group, but in overweight/obesity group, SUA had positive significant correlations with P2hCP, FCPI, PPCPI, $\triangle \mathrm{C}$-peptide, and HOMA2\%B. In female group, there were no significant correlations between SUA and insulin secretory capacity. However, in male group, SUA had positive significant correlations with insulin secretory capacity include $\mathrm{P} 2 \mathrm{hCP}, \mathrm{FCPI}, \mathrm{PPCPI}, \triangle \mathrm{C}$-peptide, and HOMA2\%B. Multiple linear regression showed that SUA was significantly associated with HOMA2\%B, but not with HOMA2IR in overweight/obesity and male group.

Conclusions: Our study shows that SUA levels within normal range were associated with $\beta$-cell function in T2DM patients with overweight/obesity or male. This finding supports that the association between SUA within normal range and insulin secretion ability differs by weight and sex. 
1 The relationship between serum uric acid within the normal range and $\beta$-cell

2 function in Chinese patients with type 2 diabetes: differences by body mass

3 index and gender

4

5 Xing Zhong, Deyuan Zhang, Lina Yang, Yijun Du, Tianrong Pan

6 Department of Endocrinology, The second Affiliated Hospital of Anhui Medical University,

7 Hefei, Anhui Province, PR China

8 Xing Zhong and Deyuan Zhang contributed equally to this article.

9

10

11 Corresponding Author:

12 Tianrong Pan

13 No.678, Furong Road, Hefei, Anhui Province, 230061, PR China

14 Email address: pantianrong1968@163.com 
15

16

17

18

19

20

21

22

23

24

25

26

27

28

29

30

31

32

33

34

35

36

37

38

39

40

41

42

43

\section{Abstract}

Background: Elevated serum uric acid (SUA) has a positive correlation with insulin secretion and insulin resistance indexes. However, whether weight- and gender-specific differences regarding the relationship between SUA within the normal range and $\beta$-cell function and insulin resistance exist is unknown in T2DM patients.

Methods: Three hundreds and eighty patients with type 2 diabetes were divided into two groups as overweight/obesity $(n=268)$ and normal weight $(n=112)$. Each group were again divided into low (LSUA) and high normal SUA (HSUA). The HbA1c, C-peptide, SUA, creatinine, and lipids profiles were measured. HOMA2IR and HOMA\%2B were estimated using fasting glucose and C-peptide by homeostasis model assessment (HOMA). Pearson's correlations and multiple linear regression analyses were conducted to assess the associations between SUA levels and islet function indexes.

Results : In overweight/obesity subgroup, the levels of BMI, FCP, P2HCP, FCPI, PPCPI, $\triangle \mathrm{C}$ peptide, HOMA2\%B and HOMA2IR were higher in HSUA group than in LSUA group. In contrast, the HbA1c, FBS, and P2hBS were lower in HSUA than in LSUA. In normal weight subgroup, there were on differences between the HSUA than LSUA group in terms of clinical characteristics. Pearson's correlations indicated that there were no significant correlations between SUA and insulin secretory capacity in normal weight group, but in overweight/obesity group, SUA had positive significant correlations with P2hCP, FCPI, PPCPI, $\triangle \mathrm{C}$-peptide, and HOMA2\%B. In female group, there were no significant correlations between SUA and insulin secretory capacity. However, in male group, SUA had positive significant correlations with insulin secretory capacity include P2hCP, FCPI, PPCPI, $\triangle \mathrm{C}$-peptide, and HOMA2\%B. Multiple linear regression showed that SUA was significantly associated with HOMA2\%B, but not with HOMA2IR in overweight/obesity and male group.

Conclusions: Our study shows that SUA levels within normal range were associated with $\beta$-cell function in T2DM patients with overweight/obesity or male. This finding supports that the association between SUA within normal range and insulin secretion ability differs by weight and sex. 


\section{Introduction}

45 Type 2 diabetes mellitus (T2DM) has become a serious issue in China with increasing incidences 46 over the past decades (Ogurtsova et al. 2017). Increasing evidence suggests that high serum uric 47 acid (SUA) level is not only associated with metabolic syndrome (MS) (Babio et al. 2015), but 48 also is regarded as a potential tool for early diagnosis of MS (Chen et al. 2016). Elevated the 49 level of SUA is associated with increased risk of T2DM and prediabetes in individuals with 50 normoglycaemia in a large population-based cohort study (Dehghan et al. 2008; van der Schaft et 51 al. 2017). However, changes in SUA and blood glucose do not exhibit a linear relationship. SUA 52 rise with increasing blood glucose concentrations in the normal and prediabetes population, 53 while SUA levels are negatively associated with HbA1c in T2DM (Kawamoto et al. 2018).

54 Progressive deterioration of islet $\beta$-cell function and insulin resistance are considered as primary 55 pathophysiological factors during the development of T2DM. SUA is the end product of an 56 exogenous pool of pruines and endogenous purine metabolism, and the final oxidation product of 57 purine metabolism in humans, which is responsible for the production of UA and damage of free 58 radicals. In hyperuricemic subjects with IGT, the failure of beta-cell function to compensate 59 variation of insulin sensitivity, compared with non-hyperuricemic (Simental-Mendia et al. 2009). 60 Furthermore, elevated SUA harbors a positive correlation with insulin secretion and insulin 61 resistance indexes in newly diagnosed T2DM patients (Hu et al. 2018), implying a possible role 62 for SUA in $\beta$-cell function. However, it remains unknown of the interaction of SUA within the 63 normal range and body mass index on $\beta$-cell function and insulin resistance in T2DM patients.

64 Therefore, we investigated the relationship between SUA within the normal range and $\beta$-cell 65 function as well as their potential confounding factors such as age, gender, diabetic duration, 66 67 gender.

\section{Materials \& Methods}

69 Study Subjects. A total of 380 patients with type 2 diabetes who visited the Second Affliated 70 Hospital of Anhui Medical University were randomly selected in this cross-sectional study. The 71 diagnosis of T2DM was according to the criteria of the American Diabetes Association (ADA). 72 The exclusion criteria were 1) with hyperuricemia defined as serum uric acid $\geqslant 420 \mathrm{umol} / \mathrm{L}$ in 73 men and $\geqslant 360 \mathrm{umol} / \mathrm{L}$ in women (Fang \& Alderman 2000), 2) with renal dysfunction defined as 
74 serum creatinine $\geq 106 \mathrm{umol} / \mathrm{L}$ in male and $\geq 97 \mathrm{umol} / \mathrm{L}$ in female or chronic kidney disease, 3)

75 patients with severe pancreatic disease and liver disease and those who suffered recent diabetic

76 ketoacidosis and hyperosmotic nonketotic diabetic coma. Written informed consent was

77 provided by all participants. The study was approved by an Ethics Committee of the Second

78 Affliated Hospital of Anhui Medical University (approval number 2017027).

79 Measurements

80 Study participants were inquired about their age and family history. Body weight, height and

81 blood pressure were measured by the diabetic nurses. Body mass index (BMI) was calculated by

82 dividing weight (in kilograms) by square of the height (in meters). Normal weight and

83 overweight/obesity were defined as BMI $<24 \mathrm{~kg} / \mathrm{m}^{2}$ and BMI $\geqslant 24 \mathrm{~kg} / \mathrm{m}^{2}$ for Chinese

84 population, respectively, according to the Working Group on Obesity in China (WGOC) BMI

85 criterias (Hou et al. 2013; Zhou 2002). Blood tests were carried out after an overnight fasting for

86 glucose, serum total cholesterol (TC), triglycerides (TG), high-density lipoprotein cholesterol

87 (HDL), low-density lipoprotein cholesterol (LDL), SUA, liver/renal functions and glycated

88 hemoglobin (HbA1c).

89 After collecting fasting blood samples, subjects received a noodle mixed-meal in patients with

90 T2DM. Blood samples were collected to measure the concentrations of glucose and C-peptide $2 \mathrm{~h}$

91 after the meal. HOMA2IR and HOMA\%2B were assessed using homeostasis model assessment

92 based on paired of FPG and fasting C-peptide measurements (http://www.dtu.ox.ac.uk/homa)

93 (Wallace et al. 2004). Insulin secretory capacity was also evaluate by CPI and $\Delta$ C-peptide.

94 Fasting CPI (FCPI) and postprandial CPI (PPCPI) were calculated by a ratio of serum C-peptide

95 to plasma glucose concentrations at baseline and $2 \mathrm{~h}$ after meal, which we termed CPR (nmol/L)/

96 FPG $(\mathrm{mmol} / \mathrm{L})$. The value of $\Delta \mathrm{C}$-peptide was defined as increment in serum C-peptide level

$97(\mathrm{nmol} / \mathrm{L})$ at $2 \mathrm{~h}$ after the meal.

98 Serum C-peptide was measured by chemiluminescent enzyme immunoassay. HbA1c was 99 measured by high performance liquid chromatography. Plasma glucose was evaluated with the 100 glucose oxidase method. TC, TG, HDL, LDL, SUA and liver/renal functions were analyzed by 101 the standardized enzymatic method.

102 Statistical analyses

103 Continuous variables were expressed as means and standard deviation (SD) or medians and 104 interquartiles. Categorical variabiles were expressed by numbers. In all the analyses, parameters 
105 with non-normal distributions were used after log transformation. For categorical variables, the 106 Chi-square test was performed, while for continuous variables, Student $t$ test was used. Pearson's 107 correlations were calculated to characterize the associations between islet function indexes and 108 SUA levels within each group. To evaluate whether SUA was an independent risk factor for $\beta$ 109 cell function in T2DM, we performed the multiple linear regression analysis. A two-tailed $p$ $110 \leq 0.05$ was considered as statistically significant. All statistical analyses were conducted with 111 SPSS software (Version 21.0).

\section{Results}

\section{Clinical and laboratory data of the patients according to BMI and SUA category}

114 The characteristic of the study patients according to BMI was shown in Table 1. The levels of 115 SBP, DBP, TG, FCP, P2HCP, FCPI, PPCPI, HOMA2\%B and HOMA2IR were higher in 116 overweight/obesity group than in normal weight group. Furthermore, the patients were divided 117 into two groups according the median SUA levels of patients with normal weight or 118 overweight/obesity, respectively (LSUA: low-normal SUA, $\leq 285$ umol/L; HSUA: high-normal 119 SUA, >285 umol/L). In overweight/ obesity subgroup, the levels of BMI, ALT, CR, FCP, 120 P2HCP, FCPI, PPCPI, $\triangle$ C-peptide, HOMA2\%B and HOMA2IR were higher in HSUA group 121 than in LSUA group. In contrast, the HbA1c, FBS, P2hBS and HDL were lower in HSUA than 122 in LSUA (Table 2). In normal weight subgroup, there were on differences between the HSUA 123 and LSUA group in terms of clinical characteristics (Table 2).

124 Correlation between SUA and insulin secretory capacity within normal or 125 overweight/obesity groups

126 The relationship between confounding factors including SUA and insulin secretory capacity 127 within normal or overweight/obesity groups was shown in Table 3. In normal weight group, 128 there were no significant correlations between SUA and insulin secretory capacity. However, in 129 overweight/obesity group, FCP, P2hCP, FCPI, PPCPI, $\triangle \mathrm{C}$-peptide, HOMA2\%B, and HOMA2IR 130 correlated positively with SUA, while HbA1c correlated negatively with SUA. After adjusting 131 for Cr, BMI, and gender, there were no significant correlations between SUA and HOMA2IR. 132 After additional adjustment for HbA1c and Duration, SUA still had positive significant 133 correlations with insulin secretory capacity include P2hCP, FCPI, PPCPI, $\triangle \mathrm{C}-$ peptide, and 134 HOMA2\%B. 
135 To further define the relation between SUA and HOMA2\%B in overweight/obesity group, 136 multiple linear regression was carried out using SUA as the dependent variable (Table 4). FCP, 137 P2HCP, FCPI, PPCPI, and $\triangle$ C-peptide were excluded from the model because of high 138 correlation with HOMA2\%B. FBS and P2hBS were also excluded because of high correlation 139 with HbA1c. SUA levels were significantly associated with HOMA2\%B in unadjusted analyses. 140 After adjustments for sex, Cr, BMI, HbA1c and Duration, SUA remained positively associated 141 with HOMA2\%B.

\section{Clinical and laboratory data of the patients according to gender and SUA category}

143 The characteristic of the study patients according to gender was shown in Table 5. There were 144234 males and 146 females. The male group were younger and had shorter duration compared to 145 the female group. Compared with female group, the levels of SUA, ALT and CR in male group 146 were higher. Furthermore, the patients were divided into two groups according the median SUA 147 levels of patients with male (LSUA: low-normal SUA, $\leq 292.0$ umol/L; HSUA: high-normal 148 SUA, $>292.0 \mathrm{umol} / \mathrm{L}$ ) or female (LSUA, $\leq 264.5 \mathrm{umol} / \mathrm{L} ; \mathrm{HSUA},>264.5 \mathrm{umol} / \mathrm{L}$ ) group, 149 respectively (Table 6). In male subgroup, the levels of BMI, ALT, HbA1c, P2HCP, FCPI, 150 PPCPI, $\triangle \mathrm{C}$-peptide, and HOMA2\%B were higher in HSUA group than in LSUA group. In 151 contrast, the HbA1c, FBS, and P2hBS were lower in HSUA than in LSUA. In female subgroup, 152 the levels of BMI, TG, CR and HOMA2IR were higher in HSUA group than in LSUA group.

\section{Correlation between SUA and insulin secretory capacity by gender category}

154 The relationship between confounding factors including SUA and insulin secretory capacity 155 within male or female groups was shown in Table 7. In male group, FCP, P2hCP, FCPI, PPCPI, $156 \Delta \mathrm{C}$-peptide and HOMA2\%B correlated positively with SUA, while HbA1c correlated negatively 157 with SUA. After adjusting for Cr and BMI, there were also significant correlations between SUA 158 and HOMA2IR. After additional adjustment for HbA1c and Duration, SUA still had positive 159 significant correlations with insulin secretory capacity include P2hCP, FCPI, PPCPI, $\triangle \mathrm{C}$ 160 peptide, and HOMA2\%B. However, in female group, SUA only correlated positively with $161 \mathrm{P} 2 \mathrm{hCP}$ and $\Delta \mathrm{C}$-peptide.

162 To further define the relation between SUA and HOMA2\%B or HOMA2IR, multiple linear 163 regression was carried out using SUA as the dependent variable (Table 8). In male group, SUA 164 levels were significantly associated with HOMA2\%B in unadjusted analyses. After adjustments 165 for Cr, BMI, HbA1c and Duration, SUA remained positively associated with HOMA2\%B. SUA 
166 levels were significantly associated with HOMA2IR in unadjusted analyses. After adjustments 167 for Cr, BMI, HbAlc and Duration, there were no significant correlations between SUA and 168 HOMA2IR. However, there were no significant correlations between SUA and HOMA2\%B and 169 HOMA2IR in female group.

170 Correlation between islet function/insulin resistance and related variables in T2DM 171 patients

172 To indentify confounding factors affecting islet function and insulin resistance, multiple linear 173 regression was again performed in T2DM patients. Independent variables such as SUA, age, 174 gender, duration, SBP, DBP, BMI, TG, TCH, LDL, HDL, ALT, CR, HbA1c were enrolled 175 (Table 9). HOMA2\%B had positive associations with BMI, SUA, age and duration and a 176 negative correlation with HbA1c. HOMA2IR had positive associations with BMI and TG and a 177 negative correlation with duration.

\section{Discussion}

179 In this study, we confirmed that SUA levels are significantly associated with HOMA2\%B in 180 T2DM patients with overweight/obesity and male group, but not in normal weight and female 181 group. In addition, we also demonstrated that other islet function indexes, such as FCPI, PPCPI, 182 and $\Delta$ C-peptide, did correlate with SUA levels in T2DM patients with overweight/obesity and 183 male group. However, our study observed the absence of a relationship between SUA and 184 HOMA2IR after adjustment for Cr, BMI, sex, HbA1c, and diabetic duration in T2DM patients 185 with overweight/obesity or male. To the best of our knowledge, this study is the first that these 186 effects of SUA within the normal range on determinants of $\beta$-cell function and insulin resistance 187 in T2DM by BMI and gender categories.

188 Uric acid is the end product of purine metabolism and derives from the conversion of 189 hypoxanthine to xanthine and of xanthine to uric acid. We observed that SUA was higher in 190 T2DM patients with overweight/obesity group than in those with normal weight group, SUA 191 within normal range independently related to obesity in T2DM. Consistent with our results, 192 several previous studies have also shown the relationship between BMI and uric acid (Han et al. 193 2018). For example, Chen et al (Chen et al. 2017) also found that prevalence of obesity steadily 194 increased across SUA quartiles in T2DM. A 10-year follow-up study demonstrated that BMI had 195 a significant independent association with uric acid in all race-sex-groups (Rathmann et al. 196 2007). Furthermore, in subjects without diabetes or hyperuricemia, SUA levels were also 
197 associated with BMI, waist circumference, and waist-to-hip ratio (Jin et al. 2013). Interestingly, 198 Zhou et al found that successful weight control, mostly $>10 \mathrm{~kg}$ weight reduction, was correlated 199 with significant uric acid reduction after 2 years observation (Zhou et al. 2017). Therefore, SUA 200 levels, even in normal range, were associated with BMI in T2DM patient.

201 In addition to strong association with BMI, SUA is also associated with $\beta$-cell function in 202 T2DM. Tang et al. (Tang et al. 2014) found that patients with higher levels of SUA had higher 203 insulin secretion, including the early phase and total insulin secretion in T2DM patients. 204 Similarly, another study (Hu et al. 2018) has also reported that SUA augments insulin secretion, 205 particularly basal insulin secretion, in the population-based study of newly diagnosed T2DM. 206 Even in nondiabetic population, higher SUA levels also significantly correlate with lower early207 phase insulin secretion (Shimodaira et al. 2014). However, the abovementioned studies do not 208 evaluate the relationship between SUA in the normal range and $\beta$-cell function. Most of prior 209 studies researching the association between SUA and $\beta$-cell function did not conduct subgroup 210 analyses by BMI categories. Our present results show that SUA in the normal range is 211 significantly associated with HOMA2\%B in T2DM patients with overweight/obesity, but not in 212 normal weight group. Although it is not possible to explain the mechanism underlying this body 213 weight difference from our study, this observation may be due to the influence of SUA levels, 214 which our study showed that SUA levels were higher in T2DM patients with overweight/obesity 215 than in those with normal weight group. Although subjects with higher SUA secrete more 216 insulin, it does not mean that high SUA is beneficial to $\beta$-cell function. SUA becomes a strong 217 oxidant in the environment of obesity (Johnson et al. 2009), which may in turn promote lipid 218 oxidation. In addition, obesity is related to elevated SUA level via both low urinary urate 219 excretion and overproduction of SUA(Matsuura et al. 1998). A recent study found that an 220 elevated level of uric acid causes $\beta$-cell injury via the NFKB-iNOS-NO signaling axis (Jia et al. 221 2013). Furthermore, Sun et al(Sun et al. 2015) found that uric acid-associated genes have an 222 impact on insulin secrction in a Chinese patients with T2DM. Finally, another study (Seyed223 Sadjadi et al. 2017) showed that the associations between SUA and diabetes risk factors are 224 largely dependent on visceral fat mass in a non-diabetic population. Physicochemical properties 225 define hyperuricemia as levels above the solubility threshold $(6.8 \mathrm{mg} / \mathrm{dl})$. With regard to 226 metabolic sequel, high-normal SUA levels are already associated with an increased risk in 227 patient with overweight/obesity. 
228 The disposition index (DI) is thought to reflect the capacity for insulin secretion adjusted for 229 insulin sensitivity and thus to provide a useful measure of $\beta$-cell function. PP-CPI, a ratio of the 230 circulating level of C-peptide to that of glucose, is correlated with clamp DI (Okuno et al. 2013). 231 In the present study, we found that PPCPI and $\Delta \mathrm{C}$-peptide had positive associations with SUA 232 levels in overweight/obesity group, but not in normal weight group. Our findings agree with 233 previous report by Tang et al (Tang et al. 2014), which shows that patients with higher SUA had 234 greater disposition indices (both DI30 and DI120). Taken together, accumulated evidence 235 suggest SUA levels may be associated with insulin secretion in T2DM patients with 236 overweight/obesity.

237 Another important finding in our study was that SUA had positive significant correlations with 238 insulin secretory capacity include P2hCP, FCPI, PPCPI, $\triangle \mathrm{C}$-peptide, and HOMA2\%B in male 239 group. Hyperuricemia affected men more commonly than women. There was a SUA difference 240 of 30-120 umol/1 between men and women (Akizuki 1982). It is previously known that estrogen 241 may promote excretion of uric acid. (Hu et al. 2018) Together, these result indicate that gender 242 differences in association between SUA within normal range and insulin secretion in patients 243 with T2DM. However, a previous study ( $\mathrm{Hu}$ et al. 2018) suggested that elevated SUA was 244 associated with insulin secretion in male and female. The mechanism underlying this sex-based 245 difference remains unclear, and requires further study.

246 The evidence of the linkage between SUA and insulin resistance in type 2 diabetes is growing, 247 but it is unclear if SUA within the normal range directly lead to declines in insulin sensitivity in 248 T2DM patients. However, our study observed the absence of a relationship between SUA within 249 normal range and insulin resistance in T2DM patients with overweight/obesity and normal 250 weight groups. Other researchers (Hu et al. 2018; Wang et al. 2011) have also demonstrated that 251 the UA levels of hyperuricemic patients have no effect on their insulin sensitivity index. Liu et 252 al. (Liu \& Ho 2011) study suggested that SUA was not associated with insulin resistance after 253 adjustment for BMI, TG, and BP. There are several possible explanations for the lack of 254 independent relationship between SUA within normal range and insulin resistance in this study. 255 Firstly, this result could be driven by SUA levels that are well within the normal range. 256 Secondly, these discrepancies could be related the techniques used for measurement of insulin 257 sensitivity. Finally, UA has an important role as an antioxidant (Lippi et al. 2008), but elevated 258 SUA may cause oxidative stress (Pasalic et al. 2012) and inhibit endothelial NO bioavailability 
259 (Sharaf El Din et al. 2017), all of which closely associated with the insulin resistance. 260 Collectively, the exact role of SUA within normal range in oxidation is still worth further 261 investigation in T2DM patients.

262 The relationship between SUA and HbA1c has been reported. For example, Kawamoto et al. 263 (Kawamoto et al. 2018) found a negative association between SUA and HbA1c was shown 264 particularly in men with $\mathrm{HbA1c} \geq 6.5 \%$. Cui et al. (Cui et al. 2016) showed that a negative 265 correlation between uric acid and $\mathrm{HbAlc}$ is conditional in newly diagnosed type 2 diabetes 266 patients. In our study, we also found that SUA within normal range negatively related to HbA1c 267 in T2DM patients with overweight/obesity. In T2DM patients with normal weight group, the 268 partial correlation analysis demonstrated the negative correlation between SUA and HbA1c, but 269 no significant difference was observed with multiple linear regression analysis. These results 270 indicated that there was negatively association between SUA, even within normal range, and $271 \mathrm{HbA} 1 \mathrm{c}$ in T2DM patients with overweight/obesity.

272 Unfortunately, this study has some limitations. Firstly, we do not analyses whether oral 273 hypoglycemic agents have effect on SUA. Sodium-glucose co-transporter 2 inhibitor (SGLT-2i) 274 could improve glycemic control and lower SUA levels in T2DM (Hao et al. 2018). However, 275 other hypoglycemic drugs, including metformin, rosiglitazone, glibenclamide and pharmacologic 276 insulin, do not have a large impact on SUA concentration (Hussain et al. 2018; Iliadis et al. 2007; 277 MacFarlane et al. 2015). In our study, the T2DM patients were treated with oral hypoglycemic 278 drugs (not including SGLT2i) and insulin. Secondly, the number of subjects enrolled was 279 relatively small. Thirdly, the relationship between SUA within normal range and oxidative stress 280 is still worth further investigation in T2DM.

281 In conclusion, our study shows that SUA levels within normal range are associated with $\beta$-cell 282 function in T2DM patients with overweight/obesity, and the relationship also displays sex-based 283 differences. However, SUA levels within normal range are not related to insulin resistance in 284 T2DM patients. This finding supports that the association between SUA within normal range and 285 insulin secretion ability differs by weight and gender.

286

287 288

\section{References}

Akizuki S. 1982. Serum uric acid levels among thirty-four thousand people in Japan. Ann Rheum Dis 41:272-274. 
289

290

291

292

293

294

295

296

297

298

299

300

301

302

303

304

305

306

307

308

309

310

311

312

313

314

315

316

317

318

319

Babio N, Martinez-Gonzalez MA, Estruch R, Warnberg J, Recondo J, Ortega-Calvo M, SerraMajem L, Corella D, Fito M, Ros E, Becerra-Tomas N, Basora J, and Salas-Salvado J. 2015. Associations between serum uric acid concentrations and metabolic syndrome and its components in the PREDIMED study. Nutr Metab Cardiovasc Dis 25:173-180. 10.1016/j.numecd.2014.10.006

Chen JH, Hsieh CH, Liu JS, Chuang TJ, Chang HW, Huang CL, Li PF, Pei D, and Chen YL. 2016. The Power of Serum Uric Acid in Predicting Metabolic Syndrome Diminishes With Age in an Elderly Chinese Population. J Nutr Health Aging 20:912-917. $10.1007 / \mathrm{s} 12603-015-0633-6$

Chen MY, Zhao CC, Li TT, Zhu Y, Yu TP, Bao YQ, Li LX, and Jia WP. 2017. Serum uric acid levels are associated with obesity but not cardio-cerebrovascular events in Chinese inpatients with type 2 diabetes. Sci Rep 7:40009. 10.1038/srep40009

Cui Y, Bu H, Ma X, Zhao S, Li X, and Lu S. 2016. The Relation between Serum Uric Acid and HbA1c Is Dependent upon Hyperinsulinemia in Patients with Newly Diagnosed Type 2 Diabetes Mellitus. J Diabetes Res 2016:7184123. 10.1155/2016/7184123

Dehghan A, van Hoek M, Sijbrands EJ, Hofman A, and Witteman JC. 2008. High serum uric acid as a novel risk factor for type 2 diabetes. Diabetes Care 31:361-362. 10.2337/dc071276

Fang J, and Alderman MH. 2000. Serum uric acid and cardiovascular mortality the NHANES I epidemiologic follow-up study, 1971-1992. National Health and Nutrition Examination Survey. JAMA 283:2404-2410.

Han T, Meng X, Shan R, Zi T, Li Y, Ma H, Zhao Y, Shi D, Qu R, Guo X, Liu L, Na L, and Sun C. 2018. Temporal relationship between hyperuricemia and obesity, and its association with future risk of type 2 diabetes. Int J Obes (Lond) 42:1336-1344. 10.1038/s41366018-0074-5

Hao Z, Huang X, Shao H, and Tian F. 2018. Effects of dapagliflozin on serum uric acid levels in hospitalized type 2 diabetic patients with inadequate glycemic control: a randomized controlled trial. Ther Clin Risk Manag 14:2407-2413. 10.2147/tcrm.s186347

Hou X, Lu J, Weng J, Ji L, Shan Z, Liu J, Tian H, Ji Q, Zhu D, Ge J, Lin L, Chen L, Guo X, Zhao Z, Li Q, Zhou Z, Shan G, Yang Z, Yang W, and Jia W. 2013. Impact of waist circumference and body mass index on risk of cardiometabolic disorder and 
320

321

322

323

324

325

326

327

328

329

330

331

332

333

334

335

336

337

338

339

340

341

342

343

344

345

346

347

348

cardiovascular disease in Chinese adults: a national diabetes and metabolic disorders survey. PLoS One 8:e57319. 10.1371/journal.pone.0057319

Hu Y, Liu J, Li H, Zhu H, Liu L, Yuan Y, Chen J, Wang Y, Hu X, and Xu Y. 2018. The association between elevated serum uric acid levels and islet beta-cell function indexes in newly diagnosed type 2 diabetes mellitus: a cross-sectional study. PeerJ 6:e4515. $10.7717 /$ peerj.4515

Hussain A, Latiwesh OB, Ali F, Younis MYG, and Alammari JA. 2018. Effects of Body Mass Index, Glycemic Control, and Hypoglycemic Drugs on Serum Uric Acid Levels in Type 2 Diabetic Patients. Cureus 10:e3158. 10.7759/cureus.3158

Iliadis F, Kadoglou NP, Hatzitolios A, Karamouzis M, Alevizos M, and Karamitsos D. 2007. Metabolic effects of rosiglitazone and metformin in Greek patients with recently diagnosed type 2 diabetes. In Vivo 21:1107-1114.

Jia L, Xing J, Ding Y, Shen Y, Shi X, Ren W, Wan M, Guo J, Zheng S, Liu Y, Liang X, and Su D. 2013. Hyperuricemia causes pancreatic beta-cell death and dysfunction through NFkappaB signaling pathway. PLoS One 8:e78284. 10.1371/journal.pone.0078284

Jin YL, Zhu T, Xu L, Zhang WS, Liu B, Jiang CQ, Yu H, Huang LM, Cheng KK, Thomas GN, and Lam TH. 2013. Uric acid levels, even in the normal range, are associated with increased cardiovascular risk: the Guangzhou Biobank Cohort Study. Int J Cardiol 168:2238-2241. 10.1016/j.ijcard.2013.01.214

Johnson RJ, Sautin YY, Oliver WJ, Roncal C, Mu W, Gabriela Sanchez-Lozada L, RodriguezIturbe B, Nakagawa T, and Benner SA. 2009. Lessons from comparative physiology: could uric acid represent a physiologic alarm signal gone awry in western society? $J$ Comp Physiol B 179:67-76. 10.1007/s00360-008-0291-7

Kawamoto R, Ninomiya D, Kasai Y, Senzaki K, Kusunoki T, Ohtsuka N, and Kumagi T. 2018. Interaction between gender and uric acid on hemoglobin A1c in community-dwelling persons. J Endocrinol Invest 41:421-429. 10.1007/s40618-017-0760-5

Lippi G, Montagnana M, Franchini M, Favaloro EJ, and Targher G. 2008. The paradoxical relationship between serum uric acid and cardiovascular disease. Clin Chim Acta 392:1-7. 10.1016/j.cca.2008.02.024 
349 Liu ZM, and Ho SC. 2011. The association of serum C-reactive protein, uric acid and

350

351

352

353

354

355

356

357

358

359

360

361

362

363

364

365

366

367

368

369

370

371

372

373

374

375

376

377 magnesium with insulin resistance in Chinese postmenopausal women with prediabetes or early untreated diabetes. Maturitas 70:176-181. 10.1016/j.maturitas.2011.07.007

MacFarlane LA, Liu CC, and Solomon DH. 2015. The effect of initiating pharmacologic insulin on serum uric acid levels in patients with diabetes: a matched cohort analysis. Semin Arthritis Rheum 44:592-596. 10.1016/j.semarthrit.2014.10.008

Matsuura F, Yamashita S, Nakamura T, Nishida M, Nozaki S, Funahashi T, and Matsuzawa Y. 1998. Effect of visceral fat accumulation on uric acid metabolism in male obese subjects: visceral fat obesity is linked more closely to overproduction of uric acid than subcutaneous fat obesity. Metabolism 47:929-933.

Ogurtsova K, da Rocha Fernandes JD, Huang Y, Linnenkamp U, Guariguata L, Cho NH, Cavan D, Shaw JE, and Makaroff LE. 2017. IDF Diabetes Atlas: Global estimates for the prevalence of diabetes for 2015 and 2040. Diabetes Res Clin Pract 128:40-50. 10.1016/j.diabres.2017.03.024

Okuno Y, Komada H, Sakaguchi K, Nakamura T, Hashimoto N, Hirota Y, Ogawa W, and Seino S. 2013. Postprandial serum C-peptide to plasma glucose concentration ratio correlates with oral glucose tolerance test- and glucose clamp-based disposition indexes. Metabolism 62:1470-1476. 10.1016/j.metabol.2013.05.022

Pasalic D, Marinkovic N, and Feher-Turkovic L. 2012. Uric acid as one of the important factors in multifactorial disorders--facts and controversies. Biochem Med (Zagreb) 22:63-75.

Rathmann W, Haastert B, Icks A, Giani G, and Roseman JM. 2007. Ten-year change in serum uric acid and its relation to changes in other metabolic risk factors in young black and white adults: the CARDIA study. Eur J Epidemiol 22:439-445. 10.1007/s10654-007$9132-3$

Seyed-Sadjadi N, Berg J, Bilgin AA, and Grant R. 2017. Visceral fat mass: is it the link between uric acid and diabetes risk? Lipids Health Dis 16:142. 10.1186/s12944-017-0532-4

Sharaf El Din UAA, Salem MM, and Abdulazim DO. 2017. Uric acid in the pathogenesis of metabolic, renal, and cardiovascular diseases: A review. $J$ Adv Res 8:537-548. 10.1016/j.jare.2016.11.004 
378 Shimodaira M, Niwa T, Nakajima K, Kobayashi M, Hanyu N, and Nakayama T. 2014. The

379

380

381

382

383

384

385

386

387

388

389

390

391

392

393

394

395

396

397

398

399

400

401

402

403

404 relationship between serum uric acid levels and beta-cell functions in nondiabetic subjects. Horm Metab Res 46:950-954. 10.1055/s-0034-1389996

Simental-Mendia LE, Rodriguez-Moran M, and Guerrero-Romero F. 2009. Failure of beta-cell function to compensate lack of insulin action in hyperuricemic subjects. Diabetes Metab Res Rev 25:535-541. 10.1002/dmrr.988

Sun X, Zhang R, Jiang F, Tang S, Chen M, Peng D, Yan J, Wang T, Wang S, Bao Y, Hu C, and Jia W. 2015. Common variants related to serum uric acid concentrations are associated with glucose metabolism and insulin secretion in a Chinese population. PLoS One 10:e0116714. 10.1371/journal.pone.0116714

Tang W, Fu Q, Zhang Q, Sun M, Gao Y, Liu X, Qian L, Shan S, and Yang T. 2014. The association between serum uric acid and residual beta -cell function in type 2 diabetes. $J$ Diabetes Res 2014:709691. 10.1155/2014/709691

van der Schaft N, Brahimaj A, Wen KX, Franco OH, and Dehghan A. 2017. The association between serum uric acid and the incidence of prediabetes and type 2 diabetes mellitus: The Rotterdam Study. PLoS One 12:e0179482. 10.1371/journal.pone.0179482

Wallace TM, Levy JC, and Matthews DR. 2004. Use and abuse of HOMA modeling. Diabetes Care 27:1487-1495.

Wang T, Bi Y, Xu M, Huang Y, Xu Y, Li X, Wang W, and Ning G. 2011. Serum uric acid associates with the incidence of type 2 diabetes in a prospective cohort of middle-aged and elderly Chinese. Endocrine 40:109-116. 10.1007/s12020-011-9449-2

Zhou BF. 2002. Predictive values of body mass index and waist circumference for risk factors of certain related diseases in Chinese adults--study on optimal cut-off points of body mass index and waist circumference in Chinese adults. Biomed Environ Sci 15:83-96.

Zhou J, Wang Y, Lian F, Chen D, Qiu Q, Xu H, Liang L, and Yang X. 2017. Physical exercises and weight loss in obese patients help to improve uric acid. Oncotarget 8:94893-94899. 10.18632/oncotarget.22046 


\section{Table 1 (on next page)}

Clinical characteristics and islet function indexes of T2DM patients by BMI 
Table 1 Clinical characteristics and islet function indexes of T2DM patients by BMI

2

\begin{tabular}{|c|c|c|c|c|}
\hline Variables & $\begin{array}{l}\text { Normal weight group } \\
\qquad(\mathrm{N}=112)\end{array}$ & $\begin{array}{l}\text { Overweight/obesity } \\
\text { group }(\mathrm{N}=268)\end{array}$ & $F / x$ & $P$ \\
\hline SUA (umol/L) & $262.5(224.3,297.0)$ & $290.5(256.0,333.0)$ & -5.08 & $<0.001$ \\
\hline Age (years) & $54.1 \pm 11.9$ & $52.1 \pm 12.0$ & 1.50 & 0.134 \\
\hline Male/Female & $63 / 49$ & $171 / 97$ & 1.38 & 0.168 \\
\hline Duration (years) & $5.0(1.0,10.0)$ & $4.0(0.3,9.7)$ & 0.51 & 0.613 \\
\hline $\mathrm{SBP}(\mathrm{mmHg})$ & $120.0(110.0,131.5)$ & $130.0(120.0,140.0)$ & -2.06 & 0.040 \\
\hline DBP (mmHg) & $77.0(70.0,84.8)$ & $80.0(76.0,90.0)$ & 0.90 & $<0.001$ \\
\hline BMI $\left(\mathrm{kg} / \mathrm{m}^{2}\right)$ & $22.3(20.6,23.4)$ & $26.1(25.4,28.2)$ & -21.3 & $<0.001$ \\
\hline $\mathrm{TG}(\mathrm{mmol} / \mathrm{L})$ & $1.38(0.88,2.12)$ & $2.00(1.22,3.12)$ & -4.24 & $<0.001$ \\
\hline TCH (mmol/L) & $4.37(3.87,5.11)$ & $4.54(3.91,5.20)$ & -1.01 & 0.315 \\
\hline LDL (mmol/L) & $2.58(2.18,2.93)$ & $2.58(2.18,3.10)$ & 0.39 & 0.697 \\
\hline HDL (mmol/L) & $1.07(0.84,1.38)$ & $1.01(0.76,1.10)$ & 2.86 & 0.004 \\
\hline ALT (U/L) & $18.0(14.0,27.0)$ & $21.0(15.0,33.0)$ & -1.87 & 0.063 \\
\hline CR (umol/L) & $68.5(58.0,81.8)$ & $73.0(62.0,85.0)$ & -1.73 & 0.084 \\
\hline HbA1c (\%) & $9.40(7.53,11.20)$ & $8.90(7.60,10.70)$ & 0.86 & 0.391 \\
\hline FPG (mmol/L) & $9.49 \pm 3.38$ & $9.32 \pm 3.03$ & 0.47 & 0.637 \\
\hline $\mathrm{P} 2 \mathrm{hPG}(\mathrm{mmol} / \mathrm{L})$ & $19.17 \pm 4.91$ & $18.69 \pm 4.37$ & 0.95 & 0.344 \\
\hline FCP (nmol/L) & $1.84(1.31,2.82)$ & $2.40(1.79,3.31)$ & -4.28 & $<0.001$ \\
\hline P2hCP (nmol/L) & $5.03(3.52,7.21)$ & $5.90(4.13,7.74)$ & -2.54 & 0.011 \\
\hline FCPI & $0.22(0.16,0.32)$ & $0.28(0.19,0.37)$ & -3.77 & $<0.001$ \\
\hline PPCPI & $1.49(0.94,2.35)$ & $1.78(1.14,2.62)$ & -2.24 & 0.026 \\
\hline$\Delta \mathrm{C}$-peptide & $2.92(1.76,4.68)$ & $3.23(1.90,4.62)$ & -1.16 & 0.245 \\
\hline НОМА $2 \%$ В & $42.2(28.0,69.0)$ & $49.7(33.9,78.4)$ & -2.39 & 0.017 \\
\hline HOMA2IR & $1.66(1.17,2.43)$ & $2.11(1.60,3.11)$ & 0.14 & $<0.001$ \\
\hline
\end{tabular}




\section{Table 2 (on next page)}

Clinical characteristics and islet function indexes of overweight/obesity and normal weight group by the median of SUA 
1

2

3

4

Table 2 Clinical characteristics and islet function indexes of overweight/obesity and normal weight group by the median of SUA

\begin{tabular}{|c|c|c|c|c|c|c|c|c|}
\hline \multirow{2}{*}{ Variables } & \multicolumn{4}{|c|}{ Overweight/obesity group } & \multicolumn{4}{|c|}{ Normal weight group } \\
\hline & LSUA & HSUA & $t / x$ & $P$ & LSUA & HSUA & $t / x$ & $P$ \\
\hline SUA (umol/L) & $<285$ & $285 \sim 420$ & & & $<285$ & $285 \sim 420$ & & \\
\hline Age (years) & $52.9 \pm 11.2$ & $51.4 \pm 12.5$ & 1.01 & 0.314 & $55.4 \pm 10.9$ & $51.7 \pm 13.5$ & 1.60 & 0.112 \\
\hline Male/Female & $62 / 56$ & $109 / 41$ & 11.58 & 0.001 & $38 / 34$ & $25 / 15$ & 0.99 & 0.320 \\
\hline Duration (years) & $4.0(0.3,10.0)$ & $4.0(0.29,9.00)$ & 0.14 & 0.886 & $6.0(1.0,10.0)$ & $4.5(0.42,10.0)$ & -0.18 & 0.861 \\
\hline SBP (mmHg) & $129.4 \pm 16.3$ & $128.7 \pm 17.3$ & 0.35 & 0.729 & $126.2 \pm 17.1$ & $122.8 \pm 20.0$ & 0.96 & 0.345 \\
\hline DBP (mmHg) & $80.5 \pm 10.2$ & $82.1 \pm 11.6$ & -1.19 & 0.235 & $76.9 \pm 9.5$ & $77.1 \pm 9.6$ & -0.07 & 0.953 \\
\hline BMI $\left(\mathrm{kg} / \mathrm{m}^{2}\right)$ & $26.5 \pm 1.9$ & $27.4 \pm 2.7$ & -3.14 & 0.002 & $21.8 \pm 1.9$ & $21.6 \pm 2.0$ & -0.17 & 0.872 \\
\hline $\mathrm{TG}(\mathrm{mmol} / \mathrm{L})$ & $1.88(1.09,2.58)$ & $2.08(1.34,3.32)$ & -1.42 & 0.156 & $1.21(0.84,2.03)$ & $1.43(1.00,2.15)$ & -0.51 & 0.614 \\
\hline $\mathrm{TCH}(\mathrm{mmol} / \mathrm{L})$ & $4.46(3.74,5.35)$ & $4.57(4.07,5.15)$ & -0.83 & 0.407 & $4.37(3.95,5.08)$ & $4.33(3.51,5.26)$ & 0.53 & 0.595 \\
\hline $\mathrm{LDL}(\mathrm{mmol} / \mathrm{L})$ & $2.58(2.19,2.95)$ & $2.59(2.17,3.13)$ & -0.59 & 0.550 & $2.58(2.31,2.93)$ & $2.58(2.02,3.15)$ & -0.37 & 0.712 \\
\hline HDL (mmol/L) & $1.07 \pm 0.38$ & $0.97 \pm 0.40$ & 2.35 & 0.020 & $1.24 \pm 0.49$ & $0.99 \pm 0.29$ & 2.94 & 0.004 \\
\hline $\operatorname{ALT}(\mathrm{U} / \mathrm{L})$ & $20.0(14.0,30.3)$ & $23.5(17.0,35.0)$ & -2.73 & 0.007 & $18.0(14.3,23.0)$ & $20.0(14.0,30.0)$ & -0.65 & 0.515 \\
\hline CR (umol/L) & $70.9 \pm 16.1$ & $75.4 \pm 14.9$ & -2.53 & 0.012 & $70.2 \pm 15.5$ & $70.7 \pm 14.8$ & -0.16 & 0.872 \\
\hline HbAlc (\%) & $9.50 \pm 2.13$ & $8.89 \pm 1.96$ & 2.40 & 0.020 & $9.32 \pm 2.32$ & $9.71 \pm 2.75$ & -0.78 & 0.434 \\
\hline $\mathrm{FPG}(\mathrm{mmol} / \mathrm{L})$ & $9.7 \pm 2.8$ & $9.0 \pm 3.2$ & 2.16 & 0.032 & $9.5 \pm 3.3$ & $9.5 \pm 3.5$ & 0.08 & 0.931 \\
\hline $\mathrm{P} 2 \mathrm{hPG}(\mathrm{mmol} / \mathrm{L})$ & $19.4 \pm 3.9$ & $18.1 \pm 4.7$ & 2.44 & 0.015 & $18.9 \pm 4.9$ & $19.5 \pm 4.9$ & -0.49 & 0.636 \\
\hline $\mathrm{FCP}(\mathrm{nmol} / \mathrm{L})$ & $2.24(1.71,3.02)$ & $2.50(1.87,3.41)$ & -2.52 & 0.012 & $1.81(1.30,2.74)$ & $1.92(1.32,3.09)$ & -0.87 & 0.388 \\
\hline $\mathrm{P} 2 \mathrm{hCP}(\mathrm{nmol} / \mathrm{L})$ & $5.00(3.63,6.73)$ & $6.52(4.87,8.43)$ & -4.45 & $<0.001$ & $4.87(3.20,6.68)$ & $5.46(3.58,7.69)$ & -0.72 & 0.474 \\
\hline FCPI & $0.24(0.17,0.34)$ & $0.31(0.22,0.42)$ & -3.82 & $<0.001$ & $0.22(0.16,0.30)$ & $0.25(0.15,0.36)$ & -0.88 & 0.381 \\
\hline PPCPI & $1.46(0.95,2.36)$ & $2.04(1.35,2.95)$ & -4.52 & $<0.001$ & $1.45(0.94,2.18)$ & $1.76(0.94,2.60)$ & -0.36 & 0.716 \\
\hline$\Delta \mathrm{C}$-peptide & $2.52(1.44,4.07)$ & $3.81(2.28,5.46)$ & -4.26 & $<0.001$ & $2.82(1.60,4.77)$ & $3.36(1.77,4.66)$ & -0.69 & 0.492 \\
\hline HOMA2\%B & $45.4(30.3,63.4)$ & $60.3(37.6,90.9)$ & -1.82 & $<0.001$ & $40.3(29.2,64.1)$ & $43.5(26.7,91.3)$ & -0.68 & 0.493 \\
\hline HOMA2IR & $2.03(1.53,2.75)$ & $2.23(1.62,3.16)$ & -4.69 & 0.007 & $1.64(1.17,2.32)$ & $1.86(1.12,2.66)$ & -0.71 & 0.477 \\
\hline
\end{tabular}

5 Values are expressed as mean \pm standard deviation (SD) or median (range $25^{\text {th }}-75^{\text {th }}$ percentile)

6 


\section{Table 3(on next page)}

Correlation of selected variables with SUA in T2DM patients with overweight/obesity group 
1 Table 3 Correlation of selected variables with SUA in T2DM patients with overweight/obesity group 2 3

4

\begin{tabular}{|c|c|c|c|c|c|c|}
\hline & \multicolumn{2}{|c|}{ Crude } & \multicolumn{2}{|c|}{ Adjusted for Cr, BMI, sex } & \multicolumn{2}{|c|}{$\begin{array}{l}\text { Adjusted for Cr, BMI, } \\
\text { sex, HbA1c, Duration }\end{array}$} \\
\hline & $r$ & $p$ & $r$ & $p$ & $r$ & $p$ \\
\hline $\mathrm{HbAlc}$ & -0.186 & 0.002 & -0.226 & $<0.001$ & & \\
\hline $\mathrm{FCP}$ & 0.194 & 0.001 & 0.130 & 0.034 & 0.115 & 0.085 \\
\hline $\mathrm{P} 2 \mathrm{hCP}$ & 0.286 & $<0.001$ & 0.274 & $<0.001$ & 0.220 & 0.001 \\
\hline FCPI & 0.268 & $<0.001$ & 0.222 & $<0.001$ & 0.142 & 0.034 \\
\hline PPCPI & 0.308 & $<0.001$ & 0.296 & $<0.001$ & 0.232 & $<0.001$ \\
\hline$\Delta \mathrm{C}$-peptide & 0.255 & $<0.001$ & 0.275 & $<0.001$ & 0.215 & 0.001 \\
\hline HOMА $2 \%$ B & 0.257 & $<0.001$ & 0.235 & $<0.001$ & 0.137 & 0.040 \\
\hline HOMA2IR & 0.142 & 0.020 & 0.082 & 0.158 & 0.105 & 0.117 \\
\hline
\end{tabular}




\section{Table 4 (on next page)}

Multiple linear regression analysis for SUA and HOMA2\%B in T2DM patients with overweight/obesity 
2

\begin{tabular}{|c|c|c|c|c|c|}
\hline & $\begin{array}{l}\text { Partial regression } \\
\text { coefficient (B) }\end{array}$ & $\begin{array}{l}\text { Standard error } \\
\text { (SE) }\end{array}$ & $\begin{array}{c}\text { Standard partial } \\
\text { regression coefficient }(\beta)\end{array}$ & $\mathrm{t}$ & $\mathrm{p}$-Value \\
\hline HOMA2\%B (unadjusted) & 0.076 & 0.018 & 0.257 & 4.337 & $<0.001$ \\
\hline $\begin{array}{l}\text { HOMA } 2 \% \text { B (adjusted for model } \\
1: \text { sex, Cr, BMI) }\end{array}$ & 0.066 & 0.017 & 0.223 & 3.930 & $<0.001$ \\
\hline $\begin{array}{l}\text { HOMA2\%B (adjusted for model } \\
\text { 2: model } 1, \text { HbA1c and Duration) }\end{array}$ & 0.049 & 0.022 & 0.182 & 2.135 & 0.013 \\
\hline
\end{tabular}

3 


\section{Table 5 (on next page)}

Clinical characteristics and islet function indexes of T2DM patients by gender 
1

2

3

8

6 are
Table 5 Clinical characteristics and islet function indexes of T2DM patients by gender

\begin{tabular}{|c|c|c|c|c|}
\hline Variables & Male $\quad(N=234)$ & Female $(\mathrm{N}=146)$ & $t / Z$ & $P$ \\
\hline SUA (umol/L) & $292.0(256.0,339.5)$ & $264.5(233.5,297.0)$ & 5.01 & $<0.001$ \\
\hline Age (years) & $49.9 \pm 12.3$ & $57.2 \pm 9.9$ & -6.03 & $<0.001$ \\
\hline Duration (years) & $3.3(0,8.0)$ & $5.5(1.0,10.0)$ & -3.38 & 0.001 \\
\hline $\mathrm{SBP}(\mathrm{mmHg})$ & $128.0(114.8,136.5)$ & $130.0(118.0,140.0)$ & -0.91 & 0.363 \\
\hline DBP (mmHg) & $80.0(75.5,90.0)$ & $80.0(70.0,84.5)$ & -3.24 & 0.001 \\
\hline BMI $\left(\mathrm{kg} / \mathrm{m}^{2}\right)$ & $25.5(23.8,27.7)$ & $25.4(23.4,27.3)$ & -1.71 & 0.088 \\
\hline $\mathrm{TG}(\mathrm{mmol} / \mathrm{L})$ & $1.99(1.12,3.13)$ & $1.54(0.96,2.29)$ & -2.89 & 0.004 \\
\hline TCH (mmol/L) & $4.44(3.87,5.20)$ & $4.52(3.94,5.15)$ & -0.32 & 0.752 \\
\hline $\mathrm{LDL}(\mathrm{mmol} / \mathrm{L})$ & $2.58(2.09,3.10)$ & $2.58(2.34,3.01)$ & -1.23 & 0.220 \\
\hline $\mathrm{HDL}(\mathrm{mmol} / \mathrm{L})$ & $0.95(0.74,1.07)$ & $1.07(0.92,1.34)$ & -4.61 & $<0.001$ \\
\hline $\operatorname{ALT}(\mathrm{U} / \mathrm{L})$ & $21.5(16.0,35.3)$ & $18.0(13.0,26.9)$ & -3.68 & $<0.001$ \\
\hline CR (umol/L) & $75.5(64.0,87.3)$ & $67.0(56.8,76.6)$ & -4.89 & $<0.001$ \\
\hline HbA1c (\%) & $9.22(7.98,10.70)$ & $8.45(7.00,11.2)$ & -1.97 & 0.051 \\
\hline $\mathrm{FBS}(\mathrm{mmol} / \mathrm{L})$ & $9.50 \pm 2.99$ & $9.16 \pm 3.35$ & 1.04 & 0.301 \\
\hline $\mathrm{P} 2 \mathrm{hBS}(\mathrm{mmol} / \mathrm{L})$ & $18.85 \pm 4.36$ & $18.80 \pm 4.81$ & 0.11 & 0.913 \\
\hline $\mathrm{FCP}(\mathrm{nmol} / \mathrm{L})$ & $2.25(1.69,3.27)$ & $2.26(1.58,3.03)$ & -1.33 & 0.182 \\
\hline $\mathrm{P} 2 \mathrm{hCP}(\mathrm{nmol} / \mathrm{L})$ & $5.53(3.94,7.34)$ & $5.74(4.21,8.04)$ & -0.94 & 0.346 \\
\hline FCPI & $0.27(0.18,0.36)$ & $0.26(0.17,0.35)$ & -0.43 & 0.671 \\
\hline PPCPI & $1.61(1.04,2.45)$ & $1.71(1.01,2.85)$ & -0.91 & 0.365 \\
\hline$\Delta \mathrm{C}$-peptide & $2.97(1.74,4.30)$ & $3.29(1.95,5.40)$ & -1.97 & 0.053 \\
\hline НОМА $2 \%$ B & $47.3(31.6,75.1)$ & $52.3(30.5,79.9)$ & -0.75 & 0.471 \\
\hline HOMA2IR & $2.04(1.47,3.09)$ & $2.02(1.31,2.63)$ & 0.45 & 0.140 \\
\hline
\end{tabular}

7 expressed as mean \pm standard deviation (SD) or median (range $25^{\text {th }}-75^{\text {th }}$ percentile)

8 


\section{Table 6(on next page)}

Clinical characteristics and islet function indexes of male and female group by the median of SUA 
1 Table 6 Clinical characteristics and islet function indexes of male and female group by the median of SUA 2

\begin{tabular}{|c|c|c|c|c|c|c|c|c|}
\hline \multirow[b]{2}{*}{ Variables } & \multicolumn{4}{|c|}{ Male group $(n=234)$} & \multicolumn{4}{|c|}{ Female group $(n=146)$} \\
\hline & $\begin{array}{c}\text { LSUA } \\
<292 \mathrm{umol} / \mathrm{L}\end{array}$ & $\begin{array}{c}\text { HSUA } \\
\geq 292 \mathrm{umol} / \mathrm{L}\end{array}$ & $t / Z$ & $P$ & $\begin{array}{c}\text { LSUA } \\
<264.5 \mathrm{umol} / \mathrm{L}\end{array}$ & $\begin{array}{c}\text { HSUA } \\
\geq 264.5 \mathrm{umol} / \mathrm{L}\end{array}$ & $t / Z$ & $P$ \\
\hline Age (years) & $50.78 \pm 12.79$ & $48.91 \pm 11.76$ & 1.16 & 0.247 & $55.90 \pm 9.27$ & $58.3 \pm 10.49$ & -1.44 & 0.153 \\
\hline Duration (years) & $4.0(0.1,8.0)$ & $3.0(0.0,7.0)$ & -0.76 & 0.447 & $5.0(1.0,10.0)$ & $6.0(1.3,10.0)$ & -0.70 & 0.481 \\
\hline SBP $(\mathrm{mmHg})$ & $\begin{array}{c}128.0(115.0 \\
136.0)\end{array}$ & $\begin{array}{c}126.0(114.0, \\
138.0)\end{array}$ & -0.35 & 0.726 & $128.0(118.0,136.0)$ & $130.0(120.0,140.0)$ & -1.26 & 0.209 \\
\hline DBP (mmHg) & $80.0(74.0,90.0)$ & $80.0(76.0,90.0)$ & -0.45 & 0.685 & $76.0(70.0,80.0)$ & $80.0(70.0,88.0)$ & -1.20 & 0.229 \\
\hline BMI $\left(\mathrm{kg} / \mathrm{m}^{2}\right)$ & $25.4(23.2,26.6)$ & $25.9(24.5,28.4)$ & -3.44 & 0.001 & $24.9(22.5,26.1)$ & $25.5(23.6,27.9)$ & -2.02 & 0.044 \\
\hline $\mathrm{TG}(\mathrm{mmol} / \mathrm{L})$ & $1.93(1.02,2.59)$ & $2.01(1.27,3.35)$ & -1.69 & 0.089 & $1.43(0.91,1.91)$ & $1.82(1.03,2.72)$ & -2.21 & 0.027 \\
\hline $\mathrm{TCH}(\mathrm{mmol} / \mathrm{L})$ & $4.38(3.80,5.19)$ & $4.57(3.92,5.18)$ & -0.99 & 0.319 & $4.55(3.95,5.22)$ & $4.43(3.91,5.05)$ & -0.55 & 0.585 \\
\hline $\mathrm{LDL}(\mathrm{mmol} / \mathrm{L})$ & $2.58(2.07,3.10)$ & $2.58(2.15,3.12)$ & -0.88 & 0.380 & $2.58(2.33,2.99)$ & $2.58(2.34,3.02)$ & -0.36 & 0.720 \\
\hline HDL (mmol/L) & $0.98(0.74,1.10)$ & $0.91(0.76,1.07)$ & -0.85 & 0.395 & $1.10(1.01,1.63)$ & $1.07(0.81,1.23)$ & -3.38 & 0.001 \\
\hline ALT (U/L) & $18.0(14.0,31.0)$ & $25.0(18.0,42.0)$ & -3.48 & $<0.001$ & $19.0(13.0,26.5)$ & $18.0(13.5,27.0)$ & -0.42 & 0.676 \\
\hline $\mathrm{CR}(\mathrm{umol} / \mathrm{L})$ & $76.0(63.0,88.0)$ & $74.0(65.0,86.0)$ & -0.03 & 0.978 & $62.0(52.5,74.0)$ & $72.0(61.5,78.5)$ & -2.95 & 0.003 \\
\hline HbAlc (\%) & $9.90(8.30,11.30)$ & $8.80(7.70,10.0)$ & 4.30 & $<0.001$ & $8.10(6.85,10.65)$ & $8.73(7.02,11.42)$ & -1.18 & 0.237 \\
\hline FBS (mmol/L) & $10.09 \pm 2.82$ & $8.89 \pm 3.05$ & 3.10 & 0.002 & $8.75 \pm 3.17$ & $9.57 \pm 3.49$ & -1.50 & 0.137 \\
\hline $\mathrm{P} 2 \mathrm{hBS}(\mathrm{mmol} / \mathrm{L})$ & $19.78 \pm 3.99$ & $17.88 \pm 4.55$ & 3.42 & 0.001 & $18.29 \pm 4.76$ & $19.32 \pm 4.82$ & -1.33 & 0.186 \\
\hline $\mathrm{FCP}(\mathrm{nmol} / \mathrm{L})$ & $2.20(1.65,2.91)$ & $2.46(1.73,3.60)$ & -1.95 & 0.051 & $2.11(1.29,2.85)$ & $2.40(1.78,3.23)$ & -1.99 & 0.046 \\
\hline $\mathrm{P} 2 \mathrm{hCP}(\mathrm{nmol} / \mathrm{L})$ & $4.85(3.54,6.67)$ & $6.19(4.48,8.06)$ & -3.95 & $<0.001$ & $5.41(3.79,7.76)$ & $6.17(4.45,8.65)$ & -1.48 & 0.138 \\
\hline FCPI & $0.22(0.17,0.33)$ & $0.31(0.22,0.47)$ & -3.93 & $<0.001$ & $0.25(0.16,0.33)$ & $0.26(0.17,0.41)$ & -0.86 & 0.392 \\
\hline PPCPI & $1.35(0.92,1.96)$ & $2.03(1.41,2.69)$ & -4.53 & $<0.001$ & $1.69(1.05,2.76)$ & $1.84(0.99,3.08)$ & -0.91 & 0.362 \\
\hline$\Delta \mathrm{C}$-peptide & $2.32(1.38,3.84)$ & $3.55(2.26,5.27)$ & -4.01 & $<0.001$ & $3.08(1.84,5.25)$ & $3.75(2.19,5.51)$ & -1.06 & 0.288 \\
\hline НОМА $2 \% \mathrm{~B}$ & $38.3(27.9,59.8)$ & $59.3(37.3,89.0)$ & -4.39 & $<0.001$ & $56.5(37.2,74.6)$ & $48.7(27.2,86.7)$ & -0.27 & 0.784 \\
\hline HOMA2IR & $1.98(1.49,2.65)$ & $2.20(1.43,3.25)$ & -1.24 & 0.214 & $1.81(1.19,2.49)$ & $2.18(1.54,2.97)$ & -2.38 & 0.017 \\
\hline
\end{tabular}

3 Values are expressed as mean \pm standard deviation (SD) or median (range $25^{\text {th }}-75^{\text {th }}$ percentile) 
Table 7 (on next page)

Correlation of SUA with selected variables in T2DM patients with male and female group 
1 Table 7 Correlation of SUA with selected variables in T2DM patients with male and female group

2

\begin{tabular}{|c|c|c|c|c|c|c|c|}
\hline & & \multicolumn{2}{|c|}{ Crude } & \multicolumn{2}{|c|}{ Adjusted for $\mathrm{Cr}$, BMI } & \multicolumn{2}{|c|}{$\begin{array}{c}\text { Adjusted for Cr, BMI, } \\
\text { HbA1c, Duration }\end{array}$} \\
\hline & & $r$ & $p$ & $r$ & $p$ & $r$ & $p$ \\
\hline \multirow[t]{8}{*}{ Male group } & HbAlc & -0.291 & $<0.001$ & -0.284 & $<0.001$ & & \\
\hline & FCP & 0.235 & 0.001 & 0.142 & 0.031 & 0.101 & 0.127 \\
\hline & $\mathrm{P} 2 \mathrm{hCP}$ & 0.331 & $<0.001$ & 0.280 & $<0.001$ & 0.163 & 0.013 \\
\hline & FCPI & 0.356 & $<0.001$ & 0.288 & $<0.001$ & 0.178 & 0.007 \\
\hline & PPCPI & 0.351 & $<0.001$ & 0.322 & $<0.001$ & 0.195 & 0.003 \\
\hline & $\Delta \mathrm{C}$-peptide & 0.293 & $<0.001$ & 0.273 & $<0.001$ & 0.147 & 0.026 \\
\hline & НОМА $2 \%$ B & 0.350 & $<0.001$ & 0.319 & $<0.001$ & 0.195 & 0.003 \\
\hline & HOMA2IR & 0.156 & 0.017 & 0.065 & 0.322 & 0.066 & 0.320 \\
\hline \multirow[t]{8}{*}{ Female group } & HbAlc & 0.013 & 0.876 & 0.011 & 0.884 & & \\
\hline & FCP & 0.165 & 0.046 & 0.108 & 0.199 & 0.113 & 0.182 \\
\hline & $\mathrm{P} 2 \mathrm{hCP}$ & 0.203 & 0.014 & 0.182 & 0.029 & 0.200 & 0.017 \\
\hline & FCPI & 0.171 & 0.039 & 0.137 & 0.101 & 0.155 & 0.066 \\
\hline & PPCPI & 0.135 & 0.104 & 0.114 & 0.175 & 0.133 & 0.116 \\
\hline & $\Delta \mathrm{C}$-peptide & 0.182 & 0.028 & 0.177 & 0.034 & 0.198 & 0.018 \\
\hline & HOMA $2 \% B$ & 0.134 & 0.106 & 0.135 & 0.108 & 0.163 & 0.053 \\
\hline & HOMA2IR & 0.149 & 0.072 & 0.090 & 0.282 & 0.094 & 0.268 \\
\hline
\end{tabular}

3 


\section{Table 8 (on next page)}

Multiple linear regression analysis for SUA and HOMA2\%B or HOMA2IR in T2DM patients by gender category 
1 Table 8 Multiple linear regression analysis for SUA and HOMA2\%B or HOMA2IRin T2DM patients by 2 gender category

3

\begin{tabular}{|c|c|c|c|c|c|c|}
\hline & & $\begin{array}{l}\text { Partial regression } \\
\text { coefficient (B) }\end{array}$ & $\begin{array}{l}\text { Standard error } \\
\text { (SE) }\end{array}$ & $\begin{array}{c}\text { Standard partial } \\
\text { regression coefficient }(\beta)\end{array}$ & $\mathrm{t}$ & $\mathrm{p}$-Value \\
\hline \multirow{8}{*}{$\begin{array}{l}\text { Male } \\
\text { group }\end{array}$} & НOMA $2 \%$ B & & & & & \\
\hline & unadjusted & 0.514 & 0.090 & 0.350 & 5.69 & $<0.001$ \\
\hline & adjusted for model 1: $\mathrm{Cr}$, BMI & 0.458 & 0.090 & 0.312 & 5.10 & $<0.001$ \\
\hline & $\begin{array}{l}\text { adjusted for model 2: } \\
\text { model } 1, \mathrm{HbA} 1 \mathrm{c} \text { and Duration }\end{array}$ & 0.319 & 0.107 & 0.217 & 2.99 & 0.003 \\
\hline & HOMA2IR & & & & & \\
\hline & unadjusted & 2.986 & 3.323 & 0.156 & 2.40 & 0.017 \\
\hline & adjusted for model 1: $\mathrm{Cr}$, BMI & 3.415 & 3.443 & 0.067 & 0.99 & 0.322 \\
\hline & $\begin{array}{l}\text { adjusted for model 2: } \\
\text { model } 1, \mathrm{HbA} 1 \mathrm{c} \text { and Duration }\end{array}$ & 3.346 & 3.359 & 0.065 & 0.99 & 0.320 \\
\hline \multirow{8}{*}{$\begin{array}{l}\text { Female } \\
\text { group }\end{array}$} & НOMA $2 \%$ B & & & & & \\
\hline & unadjusted & 0.141 & 0.087 & 0.134 & 1.626 & 0.106 \\
\hline & adjusted for model 1: Cr, BMI & 0.137 & 0.085 & 0.131 & 1.618 & 0.108 \\
\hline & $\begin{array}{l}\text { adjusted for model 2: } \\
\text { model } 1, \mathrm{HbA} 1 \mathrm{c} \text { and Duration }\end{array}$ & 0.197 & 0.101 & 0.188 & 1.949 & 0.053 \\
\hline & HOMA2IR & & & & & \\
\hline & unadjusted & 4.703 & 2.593 & 0.149 & 1.814 & 0.072 \\
\hline & adjusted for model 1: $\mathrm{Cr}$, BMI & 2.783 & 2.578 & 0.088 & 1.079 & 0.282 \\
\hline & $\begin{array}{l}\text { adjusted for model 2: } \\
\text { model } 1, \mathrm{HbA} 1 \mathrm{c} \text { and Duration }\end{array}$ & 2.940 & 2.646 & 0.093 & 1.111 & 0.268 \\
\hline
\end{tabular}




\section{Table 9 (on next page)}

Multiple linear regression analysis on related variables for islet function indexes in T2DM patients 
1

2

Table 9 Multiple linear regression analysis on related variables for islet function indexes in T2DM patients

\begin{tabular}{llcccc}
\hline & Partial regression & Standard error (SE) & $\begin{array}{c}\text { Standard partial regression } \\
\text { coefficient (B) }\end{array}$ & p-Value \\
\hline HOMA2\%B & HbA1c & -9.103 & 0.781 & -0.501 & $<0.001$ \\
& SUA & 0.127 & 0.032 & 0.177 & $<0.001$ \\
& age & 0.486 & 0.159 & 0.146 & 0.002 \\
& BMI & 1.143 & 0.522 & 0.095 & 0.029 \\
& Duration & -0.697 & 0.327 & -0.100 & 0.034 \\
& & & & & $<0.001$ \\
HOMA2IR & BMI & 0.089 & 0.018 & 0.241 & 0.001 \\
& TG & 0.076 & 0.023 & 0.165 & 0.006 \\
\hline
\end{tabular}

